\title{
Perilaku Pengendalian Bahaya Kecelakaan Kerja di Rumah Tangga Pada Masyarakat Kota Samarinda
}

\author{
Muhammad Sultan ${ }^{1 *}$ \\ ${ }^{1}$ Kesehatan dan Keselamatan Kerja, Fakultas Kesehatan Masyarakat, Universitas Mulawarman, \\ Samarinda-Indonesia \\ * corresponding author: sultan_kajang81@yahoo.co.id
}

Abstract-The potential hazards and risks in the household consist of many physical, chemical, biological, ergonomic and psychological factors. This study aims to obtain information about the accident hazard factors and efforts to control the occupational accident hazard in the household. This study uses a descriptive qualitative design with selected informants as many as 7 families. Information collection was carried out in November 2020 in Teluk Lerong Ulu Village, Samarinda City. The technique of collecting information is in-depth interviews using interview guidelines and qualitative data analysis. The results of the study obtained information that various hazard factors or risks of workplace accidents in the household include electric short circuit, danger factors from insects and venomous animals, unsafe use of kitchen knives, dangers posed when cleaning the house, and ergonomic hazards due to moving goods or objects. These hazard factors cause various complaints and accidents such as allergies, itching and skin diseases, respiratory problems, MSDS complaints, fatigue and eye health problems due to poor lighting, burns, scratches or injuries from sharp objects, pinched, crushed and crushed by falling objects. Efforts to control the danger of accidents are carried out by residents of the house such as being careful when doing activities in the kitchen, using an ironing board when ironing clothes, using stairs when doing work to reach objects in high places, storing or placing dangerous objects out of reach of children, and other precautions.

Keywords: control of hazard, household, work accident

Abstrak - Potensi bahaya dan risiko di rumah tangga begitu banyak terdiri dari bahaya faktor fisika, kimia, biologi, ergonomi dan psikologi. Penelitian ini bertujuan untuk memperoleh informasi mengenai faktor bahaya kecelakaan dan upaya pengendalian bahaya kecelakaan kerja tersebut di rumah tangga. Penelitian ini menggunakan desain kualitatif deskriptif dengan informan yang dipilih sebanyak 7 kepala keluarga. Pengumpulan informasi dilakukan pada bulan November 2020 di Kelurahan Teluk Lerong Ulu Kota Samarinda. Teknik pengumpulan informasi adalah wawancara mendalam menggunakan pedoman wawancara dan analisis data secara kualitatif. Hasil penelitian diperoleh informasi bahwa berbagai faktor bahaya atau risiko kecelakaan kerja di rumah tangga antara lain korsleting listrik, faktor bahaya dari serangga dan binatang berbisa, penggunaan pisau dapur yang tidak aman, bahaya yang ditimbulkan saat membersihkan rumah, dan bahaya ergonomis akibat memindahkan barang atau benda. Faktor bahaya tersebut menimbulkan berbagai keluhan dan kecelakaan seperti alergi gatal dan penyakit kulit, gangguan pernapasan, keluhan MSDS, kelelahan dan gangguan kesehatan mata akibat penerangan yang buruk, luka bakar, tergores atau terluka akibat benda tajam, terjepit, tertimpa dan tertindih benda jatuh. Upaya pengendalian bahaya kecelakaan tersebut perlu dilakukan oleh penghuni rumah seperti berhati-hati saat beraktivitas di bagian dapur, menggunakan meja setrika saat menyetrika pakaian, menggunakan tangga saat melakukan pekerjaan menjangkau benda di tempat tinggi, menyimpan atau menempatkan benda berbahaya dari jangkauan anak-anak, dan tindakan pencegahan lainnya.

Kata kunci: kecelakaan kerja, pengendalian bahaya, rumah tangga

\section{PENDAHULUAN}

Permasalahan keselamatan dan kesehatan kerja (K3) di Indonesia hingga kini masih merupakan pekerjaan rumah terutama bagi perusahaan yang telah memenuhi syarat sesuai ketentuan perundangan untuk menerapkan sistem manajemen K3 (SMK3). Diketahui bahwa K3 adalah segala kegiatan untuk menjamin dan melindungi K3 tenaga kerja melalui upaya pencegahan kecelakaan kerja dan penyakit akibat kerja [1]. Meskipun telah disadari bahwa bekerja di lingkungan yang memiliki potensi bahaya dapat mengakibatkan kecelakaan kerja, namun sebagian besar perusahaan belum menerapkan SMK3. Terbatas hanya pada perusahaan yang berskala besar dan mapan telah menerapkan SMK3.

Pemerintah Indonesia telah mengatur permasalahan tersebut melalui regulasi yang mengamanatkan kepada perusahaan untuk menerapkan SMK3 sesuai PP No. 50 Tahun 2012 [2] tentang Penerapan SMK3. Terdapat perusahaan yang menerapkan SMK3 tetapi masih ditemukan variabel yang belum memenuhi kriteria [3] dan belum memenuhi persyaratan SMK3 yang telah ditetapkan [4]. Kita tentu dapat membayangkan bagaimana penerapan K3 di rumah tangga yang belum ada regulasinya. Penghuni dalam sebuah rumah tangga lebih banyak 
memang tidak dapat dikategorikan sebagai tenaga kerja sesuai definisi tenaga kerja dalam Permenaker RI No. 5 tahun 2018 karena sebagian besar tidak melakukan pekerjaan guna menghasilkan barang dan/atau jasa. Penghuni rumah lebih banyak melakukan aktivitas dengan memanfaatkan benda atau peralatan kerja yang telah tersedia di rumah disesuaikan dengan kebutuhan sehari-hari, akan tetapi mereka dihadapkan dengan berbagai aktivitas yang dapat mengakibatkan kecelakaan pada saat beraktivitas di rumahnya.

Potensi bahaya di lingkungan rumah tangga sangat banyak yang di dalamnya mencakup bahaya faktor fisika, kimia, biologi, ergonomi dan psikologi. Beberapa bahaya potensial di rumah tangga seperti penerangan di ruangan yang belum memenuhi syarat kesehatan, mengangkat dan memindahkan benda melebihi beban yang dipersyaratkan serta posisi kerja yang tidak ergonomis, terdapat serangga dan bakteri pada area tertentu di dalam rumah, penggunaan bahan-bahan kimia dalam rumah tangga, hubungan yang kurang harmonis antar penghuni, dan masih banyak bahaya potensial yang terdapat dalam rumah tangga. Keberadaan faktor bahaya tersebut dapat mempengaruhi keselamatan dan kesehatan penghuni rumah.

Berbagai kemungkinan risiko kecelakaan kerja yang dapat terjadi di lingkungan rumah tangga adalah kelelahan mata saat membaca atau menulis akibat penerangan yang kurang baik, keluhan Musculoskeletal Disorder (MSDs) akibat mengangkat dan memindahkan benda, luka atau bahkan kematian akibat gigitan serangga atau binatang berbisa. Selain itu, risiko lainnya adalah keracunan atau korban meninggal dunia akibat kesalahan prosedur dalam penggunaan bahan kimia, alergi kulit dan penyakit asma akibat debu di rumah [5] luka atau patah tulang akibat perselisihan antar penghuni rumah, dan risiko lainnya.

Kecelakaan kerja di lingkungan rumah tangga dapat dipengaruhi berbagai faktor antara lain kurangnya pemahaman tentang K3 [6] dalam melaksanakan pekerjaan sehari-hari misalnya saat mencuci dan menyetrika pakaian, persepsi yang masih kurang baik dalam berperilaku aman saat menjahit [7]. Kurangnya pengetahuan dan persepsi masyarakat tentang K3 berdampak pada perilaku K3 yang kurang baik misalnya saat aktivitas mengangkat dan memindahkan kulkas masih dilakukan tidak ergonomis sehingga menimbulkan keluhan sakit pinggang atau MSDs [8]. Selain itu, penggunaan alat pelindung diri (APD) yang masih kurang dalam aktivitas menggunakan peralatan seperti pisau [9], lalai menggunakan pelindung pernafasan seperti masker saat mengangkat atau membuang sampah [10].

Tersedianya informasi yang cukup tentang perilaku K3 di lingkungan rumah tangga dapat memberikan langkah awal bagi pihak-pihak yang peduli terhadap permasalahan K3 di tingkat rumah tangga. Selain itu, penghuni rumah mampu mengidentifikasi bahaya potensial yang biasanya ditemukan di lingkungan rumah dan selanjutnya dapat melakukan upaya pengendalian bahaya yang tepat di tingkat rumah tangga. Rumah yang bebas dari potensi bahaya kecelakaan dan penyakit berdampak baik pada penghuni rumah tetap sehat dan produktif. Berdasarkan hal tersebut, maka dilakukan penelitian yang bertujuan untuk menjelaskan perilaku pengendalian bahaya kecelakaan kerja di rumah tangga.

\section{METODE}

Penelitian ini menggunakan desain kualitatif dengan informan kepala keluarga yang bertempat tinggal di RT. 27 Kelurahan Teluk Lerong Ulu Kota Samarinda yang berjumlah 37 KK. Penelitian dilaksanakan pada bulan November 2020 dengan menggunakan instrumen berupa pedoman wawancara yang telah disusun oleh peneliti disesuaikan variabel yang diteliti. Penelitian kualitatif untuk menggali pemahaman informan secara mendalam dan luas melalui wawancara [11] dan menggunakan analisis data kualitatif [12]. Pengumpulan data dilakukan pada masa pandemi COVID-19 melakukan wawancara dengan informan tetap menerapkan protokol kesehatan pencegahan COVID-19 dengan menjaga jarak, memakai masker, dan membersihkan tangan sebelum dan sesudah wawancara dilakukan menggunakan hand sanitizer.

HASIL 
Saat penelitian dilakukan, sebagian besar informan bersedia diwawancara. Selama pandemi COVID-19, aktivitas warga di tempat penelitian lebih banyak di rumah masing-masing sehingga memudahkan pengumpulan informasi. Karakteristik informan yang terlibat dalam penelitian ini sebagian besar laki-laki dengan tingkat pendidikan SMA dan jenjang sarjana. Lebih lengkapnya disajikan pada Tabel 1 berikut.

Tabel 1

Karakteritik Informan Berdasarkan Umur, Jenis Kelamin, dan Pendidikan

\begin{tabular}{ccc}
\hline Umur (tahun) & Jenis Kelamin & Pendidikan \\
\hline 48 & $\mathrm{~L}$ & SMK \\
31 & $\mathrm{P}$ & $\mathrm{S} 1$ \\
50 & $\mathrm{~L}$ & $\mathrm{SMP}$ \\
40 & $\mathrm{P}$ & $\mathrm{SMA}$ \\
39 & $\mathrm{~L}$ & $\mathrm{SMA}$ \\
42 & $\mathrm{~L}$ & $\mathrm{~S} 1$ \\
57 & $\mathrm{~L}$ & $\mathrm{~S} 1$ \\
\hline
\end{tabular}

Pengetahuan informan tentang definisi keselamatan dan kesehatan kerja di rumah tangga adalah segala sesuatu yang dilakukan dan bertujuan agar sesorang selamat dan sehat dalam melaksanakan pekerjaannya di rumah tangga. Pernyataan informan tersebut dapat dilihat pada hasil kutipan wawancara berikut ini.

".....keselamatan dan kesehatan kerja itu berarti kita selamat dan sehat dalam bekerja" (AG, 48 tahun, SW, 42 tahun)

".....aman dan tetap sehat di rumah kalau melakukan kerjaan rumah tangga" (AG, 48 tahun, YO, 40 tahun, SS, 50 tahun).

Informan memperoleh informasi tentang keselamatan dan kesehatan kerja melalui media televisi dan media online yang biasa diakses oleh mereka. Berikut kutipan hasil wawancara kepeda informan tentang sumber informasi K3 rumah tangga.

".....lihat di berita TV kalau ada kecelakaan dimana saja, juga di berita online biasanya ada disinggung" (RK, 31 tahun, $A G, 48$ tahun, $M D, 57$ tahun)

Berbagai jenis potensi bahaya dan risiko K3 di tingkat rumah tangga antara lain korsleting listrik, faktor bahaya dari serangga dan binatang berbisa, penggunaan pisau dapur yang tidak aman, bahaya yang ditimbulkan saat membersihkan rumah, dan bahaya ergonomis akibat memindahkan barang atau benda. Berikut hasil kutipan wawancara dengan informan mengenai pengetahuan jenis potensi bahaya yang terdapat di rumah tangga.

".....listrik korsleting, banyak nyamuk juga binatang kayak tikus, di dapur juga kalau lagi masak pakai pisau, bersih-bersih rumah lah intinya, pindah-pindah barang" (RK, 31 tahun, ID, 40 tahun, SW, 42 tahun, MD, 57 tahun) 
Dampak adanya potensi bahaya dan risiko di rumah tangga seperti luka pada tangan, luka dan bahkan kematian akibat kesetrum listrik, keluhan sakit pinggang, dan terjatuh. Penyataan informan tersebut berdasarkan hasil kutipan wawancara yang dilakukan sebagai berikut.

".....tangan terluka, kesetrum listrik, luka, sakit pinggang, jatuh dari kursi" (AG, 48 tahun, ID, 40 tahun, SW, 42 tahun)

Adapun persepsi informan tentang K3 di rumah tangga, potensi bahaya di rumah, dampak bahaya di rumah, dan penerapan K3 dalam beraktivitas di rumah dapat dilihat pada hasil kutipan wawancara berikut.

".....penting diketahui sebelum bekerja jadinya bisa dicegah, sangat perlu dilakukan biar aman, maunya sich dilakukan biar sehat" (AG, 48 tahun, RK, 31 tahun, SS, 50 tahun)

".....bahaya itu di rumah khan banyak sekali jadi jangan dilihati saja lah, saking banyak macamnya makanya harus ditahu dulu" (RK, 31 tahun, SS, 50 tahun)

".....yah kalau dibiarkan bisa celaka, apalagi kalau lama-lama dilihatin saja bisa sakit" (ID, 40 tahun, SW, 42 tahun)

".....bujur lah (benar) kalau dilakukan, perlu diterapkan kalau mau selamat dan sehat" (RK, 31 tahun, ID, 40 tahun)

Informan melakukan tindakan atau praktik pengendalian faktor bahaya atau risiko di tingkat rumah tangga seperti berhati-hati saat beraktivitas di bagian dapur dan menggunakan meja setrika saat menyetrika pakaian. Praktik lainnya seperti menggunakan tangga saat melakukan pekerjaan menjangkau benda di tempat tinggi, menyimpan atau menempatkan benda berbahaya dari jangkauan anak-anak, dan tindakan pencegahan lainnya.

“.....berhati-hati saat memasak, menyediakan meja setrika, menyediakan tangga, menyapu bersih, simpan barang jauh dari jangkauan anak kecil, siapkan meja belajar, bersih-bersih halaman rumah setiap hari, membersihkan kamar mandi setiap hari, perbaikan listrik oleh petugas PLN, meminta bantuan jika memindahkan barang" (AG, 48 tahun, RK, 31 tahun, SS, 50 tahun, ID, 40 tahun)

Berbagai keluhan atau gangguan kesehatan yang sering dirasakan saat atau setelah melakukan pekerjaan di rumah dan bahkan informan pernah mengalami kecelakaan saat beraktivitas di rumah. Berikut hasil kutipan wawancara informan tentang keluhan dan kecelakaan yang pernah dialami.

".....sakit pinggang, mata saya cepat capek kalau tidak terang, gatal-gatal si kecil, batuk-batuk, kadang emosi kalau lama-lama ngajari anak belum paham" (ID, 40 tahun, SW, 42 tahun, MD, 57 tahun)

".....terjatuh saat pasang hiasan dinding, kepeleset di kamar mandi, luka tangan karena pisau dapur, luka digigit tikus, kesetrum listrik, terkilir waktu mengangkat, terjepit pintu, kejatuhan barang dari atas" (AG, 48 tahun, RK, 31 tahun, SS, 50 tahun, ID, 40 tahun, YO, 39 tahun, SW, 42 tahun, MD, 57 tahun).

Informan dalam penelitian ini mengatakan bahwa K3 adalah melakukan aktivitas atau pekerjaan dengan memperhatikan keselamatan dan kesehatan saat bekerja. Menurut 
Permenkes RI No. 5 tahun 2018, K3 adalah segala kegiatan untuk menjamin dan melindungi K3 tenaga kerja melalui upaya pencegahan kecelakaan kerja dan penyakit akibat kerja [1].

\section{BAHASAN}

Ruang lingkup K3 tidak hanya terbatas pada pekerja sektor formal tetapi juga pada sektor informal termasuk di lingkungan rumah tangga. Informasi mengenai K3 biasanya diperoleh dari berbagai sumber antara lain media elektronik seperti televisi dan media online lainnya. Media elektronik dan media sosial online seperti Facebook, Whatsapp, Twitter dan lainnya merupakan sarana penyebaran informasi dan isu kesehatan di lingkungan masyarakat [13] termasuk informasi penting lainnya [14]. Oleh karena itu, pemanfaatan media elektronik dan media sosial online dengan benar sangat membantu masyarakat dalam mengakses informasi yang dibutuhkan.

Berbagai jenis potensi bahaya di lingkungan rumah tangga seperti faktor bahaya fisika, kimia, biologi, ergonomi, dan psikologi [1]. Banyaknya jenis aktivitas di rumah tangga menimbulkan berbagai macam potensi bahaya seperti penerangan yang kurang dan bahkan silau pada ruangan atau aktivitas tertentu. Faktor bahaya lainnya seperti penggunaan listrik yang tidak aman, keberadaan serangga dan binatang berbisa, penggunaan benda tajam yang tidak perlu, debu pada dinding dan benda yang digunakan. Selain itu, penggunaan bahan kimia dapat berupa cairan deterjen dan gas elpiji, mengangkat atau memindahkan barang tidak memenuhi beban yang diperbolehkan dan sikap kerja tidak ergonomis, perselisihan atau kesalahpahaman antarpenghuni rumah, dan masih banyak lagi potensi bahaya lainnya.

Potensi bahaya tersebut jika tidak dikelola dengan benar, maka dapat mengakibatkan dampak kesehatan dan kecelakaan yang serius bagi penghuninya seperti kelelahan pada mata saat mengerjakan sesuatu yang membutuhkan ketelitian seperti menjahit, membaca, mengetik atau menulis. Penerangan yang buruk akan memudahkan seseorang mengalami kelelahan mata seperti pada aktivitas menjahit pakaian yang memerlukan ketelitian [15]. Selain itu, intensitas penerangan juga berdampak pada gangguan kesehatan mata berupa Computer Vision Syndrome (CVS) [16]. Intensitas penerangan di area atau ruangan tertentu di rumah sebaiknya memenuhi syarat yang telah ditetapkan misalnya aktivitas menulis atau mengetik dalam waktu relatif lama memerlukan intensitas penerangan 500-1000 Lux [1]. Selain itu, upaya lainnya yang dapat dilakukan yaitu mengganti sumber penerangan yang sesuai jenis aktivitas dan membersihkan sumber penerangan buatan secara rutin.

Penghuni rumah dapat mengalami luka bakar akibat kesetrum listrik dan bahkan korban meninggal dunia. Kasus kecelakaan berupa luka bakar banyak dialami masyarakat akibat instalasi listrik tidak baik, penggunaan barang elektronik dengan energi listrik yang tidak benar dan pemakaian listrik tidak sesuai prosedur juga dapat meningkatkan risiko terjadinya musibah kebakaran di lingkungan masyarakat [17]. Upaya pencegahan dan pengendalian dampak penggunaan listrik di rumah dapat dilakukan dengan perbaikan ulang instalasi listrik oleh petugas PLN yang terdekat, mengganti barang elektronik yang tidak layak fungsi, dan menghindari tindakan ilegal pemakaian listrik yang tidak sesuai prosedur yang telah ditetapkan PLN.

Aktivitas menyajikan makanan dan minuman di rumah untuk sarapan, makan siang dan malam juga dapat berisiko tergores atau terluka akibat benda tajam, keluhan MSDs karena stasiun kerja tidak ergonomis, tersiram air dan makanan panas. Pengendalian bahaya tersebut dapat dilakukan dengan mengganti dan pemeliharaan peralatan masak yang digunakan [18], mendesain stasiun kerja dan area dapur disesuaikan dengan antropometri pemakainya [19], dan menggunakan alat pelindung diri (APD) yang sesuai seperti pakaian pelindung panas berupa celemek dan sarung tangan.

Risiko kecelakaan kerja lainnya yang dapat dialami penghuni rumah saat beraktivitas keseharian adalah terjepit saat menutup pintu dan jendela rumah. Selain itu, risiko tertimpa atau tertindih akibat kejatuhan benda di rumah. Menutup atau membuka pintu dan jendela rumah setiap hari dilakukan penghuni rumah dan tidak jarang dari mereka mengalami luka 
tangan akibat terjepit. Begitu pula penempatan hiasan, benda atau peralatan yang biasanya digunakan di rumah pada tempat tinggi seperti di dinding dan di atas lemari dapat menyebabkan patah tulang dan luka serius akibat jatuh saat pemasangan atau penyimpanan, kejatuhan dan tertimpa benda tersebut. Oleh karena itu, perlu dilakukan upaya pengendalian bahaya dan risiko seperti memasang benda pada ketinggian dengan menggunakan tangga dan menggantungnya dengan mempertimbangkan jarak dari tempat biasa berkumpul penghuni rumah. Hal lainnya yang dapat dilakukan seperti menutup dan membuka pintu atau jendela rumah oleh penghuni rumah yang dewasa dan tidak perlu membuka atau menutupnya jika tidak diperlukan.

Keluhan kesehatan penghuni rumah dari potensi bahaya biologi yang biasanya dialami berupa alergi gatal dan penyakit kulit karena paparan faktor biologi seperti bakteri, jamur, dan gigitan serangga [20]. Akibat gigitan serangga dan binatang berbisa di rumah dapat berdampak serius berupa luka dan bahkan korban meninggal dunia. Upaya pengendalian faktor bahaya biologi yang diakibatkan gigitan binatang berbisa seperti ular agar segera ke rumah sakit untuk mencegah kejadian fatal [21], penyediaan obat-obatan sebagai imunotherapy pada anak yang alergi tungau di rumah [22] dan aman dalam penggunaannya [23]. Selain itu, penghuni rumah perlu menerapkan perilaku hidup bersih dan sehat (PHBS) berdasarkan indikator PHBS Kementerian Kesehatan RI [24] untuk mencegah penyakit di rumah tangga terutama penyakit menular seperti penyakit kulit akibat jamur, [25]. Upaya pengendalian faktor biologi tersebut juga bertujuan untuk mencegah penyakit pernafasan seperti infeksi saluran pernafasan akut (ISPA) terutama pada balita [26].

Penggunaan bahan kimia seperti gas elpiji yang tidak aman dan debu yang menempel di lantai, dinding, dan langit-langit rumah dapat menimbulkan gangguan kesehatan penghuni berupa batuk-batuk atau gangguan pernafasan lainnya, keracunan dan bahaya kebakaran. Kadar debu dalam rumah dapat dipengaruhi ketersediaan ventilasi, frekuensi membuka pintu dan jendela rumah, dan letak rumah yang ramai akan lalu lintas jalan dan debu tersebut dapat mempengaruhi gangguan ISPA terutama pada balita [27]. Kejadian kebakaran di rumah tangga dari penggunaan bahan kimia gas dapat disebabkan ketidaktahuan pengguna akan bahaya yang akan terjadi dan kesalahan dalam penggunaannya [28]. Oleh karena itu, diperlukan upaya pengendalian bahaya seperti membersihkan halaman, lantai, dinding, dan langit-langit rumah secara rutin, membuka atau menutup pintu dan jendela rumah jika diperlukan, menyediakan ventilasi rumah yang cukup, dan pelatihan perilaku keselamatan [29] khususnya keselamatan penggunaan tabung gas elpiji di rumah tangga.

Keluhan kesehatan yang paling sering dirasakan penghuni rumah saat dan setelah melakukan aktivitas sehari-hari adalah MSDs dengan keluhan umum seperti sakit atau nyeri otot dan kesemutan pada bagian tubuh tertentu. Hal ini dapat disebabkan jika penghuni rumah melakukan pekerjaan tidak ergonomis [30], misalnya mengangkat dan memindahkan benda dengan postur kerja tidak sesuai [31],(32) atau berat beban yang diangkat secara manual berlebihan [33] tanpa menggunakan alat bantu angkut. Upaya pengendalian bahaya ergonomi di tingkat rumah tangga seperti mengangkat dan memindahkan benda dilakukan bersama-sama atau menggunakan alat bantu angkut dan menempatkan benda pada batas jangkauan tangan. Selain itu, upaya pengendalian faktor bahaya ergonomi juga dapat dilakukan seperti menghindari pekerjaan yang belum pernah dilakukan sebelumnya dan sebaiknya pekerjaan tersebut diserahkan ke anggota keluarga lainnya yang berpengalaman.

Kecelakaan kerja dan penyakit atau gangguan kesehatan yang dapat ditimbulkan dari aktivitas atau pekerjaan disebabkan tindakan tidak aman (unsafe act) dan kondisi tidak aman (unsafe condition). Oleh karena itu, upaya pengendalian bahaya dan risiko sebaiknya lebih ditujukan pada perbaikan perilaku K3 penghuni rumah atau intervensi manusia human approach) dalam beraktivitas sehari-hari dan tetap melakukan pengendalian bahaya yang disebabkan kondisi tidak aman.

Secara umum upaya pengendalian bahaya dan risiko sesuai Permenkes RI No. 5 tahun 2018 (1) dapat diimplementasikan di tingkat rumah tangga. Upaya pengendalian tingkat rumah 
tangga antara lain, 1) menghilangkan atau eliminasi (elimination) sumber potensi bahaya dari bahan, proses, operasi, atau peralatan yang digunakan di rumah, 2) subtitusi (subtitution) atau mengganti bahan, proses, operasi atau peralatan dari yang berbahaya menjadi tidak berbahaya, 3) pengendalian teknik (engineering control) yaitu upaya memisahkan sumber bahaya dari penghuni rumah dengan memasang sistem pengaman pada alat, mesin, dan atau area kerja, 4) pengendalian administratif (administrative control) merupakan upaya pengendalian dari sisi penghuni rumah agar dapat melakukan pekerjaan secara aman, 5) dan penggunaan APD.

\section{SIMPULAN}

Jenis potensi bahaya di lingkungan rumah tangga seperti faktor bahaya fisika, kimia, biologi, ergonomi, dan psikologi. Bahaya tersebut seperti penerangan yang kurang dan bahkan silau pada ruangan atau aktivitas tertentu, penggunaan listrik yang tidak aman, keberadaan serangga dan binatang berbisa, penggunaan benda tajam, debu, bahan kimia, aktivitas mengangkat atau memindahkan barang tidak ergonomis, perselisihan antar penghuni rumah, dan bahaya lainnya. Bahaya dan risiko K3 yang dapat dialami penghuni rumah seperti kelelahan dan gangguan kesehatan mata akibat penerangan yang buruk, luka bakar akibat kesetrum listrik dan bahkan korban meninggal dunia, risiko tergores atau terluka akibat benda tajam, terjepit, tertimpa atau tertindih akibat kejatuhan benda. Keluhan kesehatan penghuni rumah dari potensi bahaya biologi seperti alergi gatal dan penyakit kulit, batuk, atau gangguan pernafasan seperti ISPA, dan keluhan MSDs. Bahaya dan risiko tersebut jika tidak dikelola dengan benar dapat mengakibatkan keluhan kesehatan dan kecelakaan yang serius bagi penghuni rumah. Oleh karena itu, dibutuhkan upaya pengendalian bahaya dan risiko yang tepat disesuaikan dengan aktivitas keseharian penghuni rumah tangga. Selain itu, perlu dilakukan penelitian intervensi pengendalian bahaya dan risiko $\mathrm{K} 3$ yang tepat di tingkat rumah tangga agar masyarakat tetap sehat dan produktif.

\section{PUSTAKA ACUAN}

1. Permenaker RI No. 5. Peraturan Menteri Ketenaga Kerjaan Republik Indonesia No. 5 tahun 2018 tentang Keselamatan dan Kesehatan Kerja Lingkungan Kerja. Jurnal Pendidikan, Teknologi dan Kejuruan. 2018.

2. PP No 50 TAHUN 2012. Sistem Manajemen K3. SMK3. 2012;

3. Herlinawati H, Zulfikar AS. Analisis Penerapan Sistem Manajemen Keselamatan Dan Kesehatan Kerja (SMK3). J Kesehat. 2020;

4. Allison C, Prastawa H. Analisis Penerapan SMK3 pada PT Indonesia Power UBP MRICA Banjarnegara. Ind Eng Online J. 2019;

5. Yang L, Zhu R. Immunotherapy of house dust mite allergy. Human Vaccines and Immunotherapeutics. 2017.

6. Mulyani Y, Gardiarini P, Karim S. Penerapan Kesehatan Keselamatan Kerja (K3) Di UMKM Laundry Balikpapan. J ABDINUS J Pengabdi Nusant. 2019;

7. Wijaya W, Rahayuningsih S, Komari A. Tingkat Perilaku Aman Tenaga Kerja Bagian Jahit Dengan Menggunakan Metode Antecedent Behavior Consequence Di Pt. Glow. Jurmatis J IIm Mhs Tek Ind. 2019;

8. Arminas. Perancangan Fasilitas Kerja dan Perbaikan Postur Kerja pada Aktivitas Manual Material Handling Karyawan Toko Mega Mas Elektronik Makassar. J Ergon dan K3. 2016;

9. Rudyarti E. Hubungan Pengetahuan Keselamatan Dan Kesehatan Kerja Dan Sikap Penggunaan Alat Pelindung Diri Dengan Kejadian Kecelakaan Kerja Pada Pengrajin Pisau Batik Di Pt. X. J Kesehat Masy. 2017;

10. Liswanti Y. Faktor-Faktor Yang Berhubungan Dengan Kepatuhan Penggunaan Alat Pelindung Diri (Apd) Serta Kaitannya Terhadap Status Kesehatan Pada Petugas Pengumpul Sampah Rumah Tangga Di Kota Tasikmalaya Tahun 2014. J Kesehat Bakti Tunas Husada J Ilmu-ilmu Keperawatan, Anal Kesehat dan Farm. 2015; 
11. Jamshed S. Qualitative research method-interviewing and observation. J Basic Clin Pharm. 2014;

12. Ridder HG, Miles MB, Michael Huberman A, Saldaña J. Qualitative data analysis. A methods sourcebook. Zeitschrift fur Pers. 2014;

13. Fitriani Y. Analisis Pemanfaatan Berbagai Media Sosial sebagai Sarana Penyebaran Informasi bagi Masyarakat. Paradig - J Komput dan Inform. 2017;

14. Sohana Abdul Hamid. Pengaruh Media Massa Terhadap Masyarkat. J Soc Sci Humanit. 2016;

15. Jasna J, Dahlan M. Hubungan Intensitas Pencahayaan Dengan Kelelahan Mata Pada Pekerja Penjahit Di Kabupaten Polewali Mandar. J-KESMAS J Kesehat Masy. 2019;

16. Insani Y. Hubungan Jarak Mata dan Intensitas Pencahayaan terhadap Computer Vision Syndrome. J Manaj Kesehat Yayasan RSDr Soetomo. 2018;

17. Siahaan SD, Monoarfa A, Hatibie M. Profil Penderita Luka Bakar Akibat Listrik Di Blu Rsu Prof. Dr. R. D. Kandou Manado Periode Agustus 2009? Agustus 2012. e-CliniC. 2013;

18. Braglia M, Di Donato L, Gabbrielli R, Marrazzini L. The house of safety: A novel method for risk assessment including human misbehaviour. Saf Sci. 2018;

19. Setiawan HS. Pengaruh Ergonomi dan Antropometri bagi User Gudang Bahan PT. MI guna Meningkatkan Produktivitas Serta Kualitas Kerja. STRING (Satuan Tulisan Ris dan Inov Teknol. 2017;

20. Kurniawan. Diagnosis dan Terapi Skabies. Cermin Dunia Kedokt. 2020;

21. Cindy Nurul Afni A, Nasrul Sani F. Pertolongan Pertama Dan Penilaian Keparahan Envenomasi Pada Pasien Gigitan Ular. J Kesehat Kusuma Husada. 2020;

22. Maloney J, Prenner BM, Bernstein DI, Lu S, Gawchik S, Berman G, et al. Safety of house dust mite sublingual immunotherapy standardized quality tablet in children allergic to house dust mites. Ann Allergy, Asthma Immunol. 2016;

23. Mosbech H, Canonica GW, Backer V, De Blay F, Klimek L, Broge L, et al. SQ house dust mite sublingually administered immunotherapy tablet (ALK) improves allergic rhinitis in patients with house dust mite allergic asthma and rhinitis symptoms. Ann Allergy, Asthma Immunol. 2015;

24. Kesehatan D. Rumah Tangga Sehat Dengan Perilaku Hidup Bersih Dan Sehat. Pusat Promosi Kesehatan Departemen Kesehatan RI. 2009;

25. Raksanagara A, Raksanagara A. Perilaku Hidup Bersih Dan Sehat Sebagai Determinan Kesehatan Yang Penting Pada Tatanan Rumah Tangga Di Kota Bandung. J Sist Kesehat. 2016;

26. Raenti RA, Gunawan AT, Subagiyo A. Hubungan Faktor Lingkungan Fisik Rumah Dan Perilaku Hidup Bersih Dan Sehat Dengan Kejadian Infeksi Saluran Pernapasan Akut Pada Balita Di Wilayah Kerja Puskesmas 1 Purwokerto Timur Tahun 2018. Bul Keslingmas. 2019;

27. Azhar K, Dharmayanti I, Mufida I. Kadar Debu Partikulat (PM2,5) dalam Rumah dan Kejadian ISPA pada Balita di Kelurahan Kayuringin Jaya, Kota Bekasi Tahun 2014. Media Penelit dan Pengemb Kesehat. 2016;

28. Harjanto NT, Suliyanto, I ES. Manajemen Bahan Kimia Berbahaya Dan Beracun Sebagai Upaya Keselamatan Dan Kesehatan Kerja Serta Perlindungan Lingkungan. No 08/ Tahun IV Oktober 2011 ISSN 1979-2409. 2011;

29. Suryanto, Anam, A., Andodo C. Pencegahan Kecelakaan Kerja Berbasis Human and Technical Approach Di Purwokerto Utara. J Kesmas Indones. 2016;

30. Mayasari D, Saftarina F. Ergonomi Sebagai Upaya Pencegahan Musculoskletal Disorders. J Kedokt Univ Lampunh. 2016;

31. Iksan Hananto. Hubungan Tingkat Risiko Postur Kerja Dengan Tingkat Risiko Musculosskeletal Disorder Pada Pekerja Kuli Panggul Di Pasar Legi Surakarta. Hub Tingkat Risiko Postur Kerja Dengan Tingkat Risiko Musculosskeletal Disord Pada Pekerja Kuli Panggul Di Pasar Legi Surakarta. 2019;

32. Hendrarini L, Suwarni A. Faktor faktor kejadian musculoskeletal disorders (MDS) pada 
Muhammad, S., Perilaku Pengendalian Bahaya Kecelakaan Kerja di Rumah Tangga Pada Masyarakat Kota Samarinda, KELUWIH: Jurnal Kesehatan dan Kedokteran, Vol.2(2), 82-90, Juni 2021.

tenaga kerja informal (kuli panggul) di Pasar Giwangan Yogyakarta. J Teknol Kesehat. 2016;

33. Muslimah E, Pratiwi I, Rafsanjani F. Analisis Manual Material Handling Menggunakan Niosh Equation. J Ilm Tek Ind. 2016; 